\title{
Elementos gímnicos presentes nas brincadeiras no parque de uma instituição escolar infantil: uma abordagem com foco nos padrões básicos de movimento
}

\section{RESUMO}

A pesquisa objetivou identificar a presença de elementos gímnicos nas brincadeiras de crianças em um parque construído com material alternativo (pneus) no contexto de uma instituição de Educação Infantil no Município de Diamantina-MG, amparado no referencial dos Padrões Básicos de Movimento (PBMs) elencados por Russel (2010). Com caráter descritivo, utilizou-se como técnica de coleta das informações a observação sistemática, realizadas durante horários destinados ao livre brincar, com presença do professor regente. Neste sentido, a pesquisa contou com fotos, filmagens e anotações realizadas em diário de campo, possibilitando interpretar e categorizar os movimentos infantis na abordagem dos PBMs. Os resultados permitiram identificar movimentos realizados espontaneamente pelas crianças e organizá-los a partir da perspectiva dos PBMs apontando que tais ações motoras permeiam o universo infantil através das brincadeiras e experimentações corporais no parque, as quais precisam ser estimuladas e vivenciadas pelas crianças no intuito de ampliar os saberes e experiências corporais.

PALAVRAS-CHAVE: Ginástica; Educação infantil; Brincar
Juliana Nogueira Pontes Nobre

Mestre Saúde, Sociedade e Ambiente Universidade Federal dos Vales do Jequitinhonha e Mucuri, Diamantina, Minas Gerais, Brasil Junobre2007@yahoo.com.br

https://orcid.org/0000-0002-9876-1136

Ana Flávia da Silva

Graduada em Educação Física pela Universidade Federal dos Vales do Jequitinhonha e Mucuri-UFVJM,

Diamantina, Minas Gerais Brasil anaflaviasilva525@gmail.com

https://orcid.org/0000-0001-8323-896X

Priscila Lopes

Doutora em Educação Física

Professora titular do Departamento de Educação Física da Universidade Federal do Vale do Jequitinhonha e Mucuri, Diamantina. Minas Gerais, Brasil. priscila.lopes@ufvjm.edu.br https://orcid.org/0000-0002-1896-1841

\section{Claudia Mara Niquini \\ Doutora em Educação}

Professora adjunta do Departamento de Educação Física da Universidade Federal do Vale do Jequitinhonha e Mucuri, Diamantina. Minas Gerais, Brasil. claudia.niquini@ufvjm.edu.br https://orcid.org/0000-0003-4583-0107 


\title{
Gymnastic elements present in the play in the park of a children's school institution: an
} approach focusing on basic movement patterns

\begin{abstract}
The research aimed to identify the presence of gymnastic elements in children's play in a park built with alternative material (tires) in the context of an educational institution for early childhood education in the municipality of Diamantina-MG, supported by the Basic Movement Standards (BMS), listed by Russel (2010). With a descriptive character, systematic observation was used as a technique for collecting information, performed during times intended for free play, with the presence of the conducting teacher. In this sense, the research included photos, footage and notes taken in a field diary, making it possible to interpret and categorize children's movements in the approach to PBMs. The results allowed to identify movements spontaneously performed by children and organize them from the perspective of PBMs, pointing out that these patterns permeate the children's universe through body play and experimentation, in which they need to be stimulated and experienced by children, in order to expand body knowledge.
\end{abstract}

KEYWORDS: Gymnastics; Early childhood education; Play

Elementos gimnásticos presentes en el juego en el parque de una institución escolar infantil: un enfoque centrado en los patrones de movimiento básicos

\section{RESUMEN}

La investigación tuvo como objetivo identificar la presencia de elementos gimnásticos en el juego infantil en un parque construido con material alternativo (llantas) en el contexto de una institución educativa para la educación infantil en el municipio de Diamantina-MG, sustentado en los Estándares Básicos de Movimiento (PBM), enumerado por Russel (2010). Con carácter descriptivo, se utilizó la observación sistemática como técnica de recolección de información, realizada en tiempos destinados al juego libre, con la presencia del maestro director. En este sentido, la investigación incluyó fotografías, metraje y notas tomadas en un diario de campo, lo que permitió interpretar y categorizar los movimientos de los niños en el abordaje de los PBM. Los resultados permitieron identificar movimientos realizados espontáneamente por los niños y organizarlos desde la perspectiva de los PBM, señalando que estos patrones impregnan el universo infantil a través del juego corporal y la experimentación, en la que necesitan ser estimulados y experimentados por los niños, con el fin de ampliar el conocimiento corporal.

PALABRAS-CLAVE: Gimnasia; Educación infantil; Jugar 


\section{INTRODUÇÃO}

A infância é um momento fundamental na construção histórico social do ser humano visto que é a partir deste período da vida que se inicia o processo de construção de identidade (GASPAR, 2017). É considerado um período fértil para as aprendizagens e elaboração de diferentes sentidos, significados e formas de manifestações do pensamento que acontece principalmente no momento do brincar (CORSARO, 2011).

Neste sentido, o brincar promove interações entre os pares, pois oportuniza convivência e interação com outro ser humano. Este momento propicia aprendizagem sobre apropriação e produção da cultura, sobre a autonomia experimentando a liberdade, a escolha, as manifestações de humor e prazer (NICOLIETO et al., 2019). É por meio de tais práticas sociais vivenciadas com o brincar que as interações são experimentadas e assim a criança educa-se, aprende a esperar a sua vez, a ceder o brinquedo, a brincar junto, etc. Assim, tais práticas são por si só educativas e podem, também, envolver a movimentação corporal.

No que toca o desenvolvimento da criança, os sentidos permeiam o movimentar e é por meio deste que o desenvolvimento acontece (GALLAHUE; OZMUN, 2013). Desta forma, a possibilidade de movimentar-se proporciona uma variedade de experimentações corporais, as quais podem ser expressas através do cotidiano das brincadeiras permitindo novas descobertas (TONIETTO; GARANHANI, 2017). As novas descobertas constituem o repertório de movimentos, constructo importante para o ser humano, pois "o se-movimentar" é de grande importância biológica, psicológica, social e cultural para a formação das crianças (GONZALEZ; SCHWENGBER, 2012).

Logo, todo ambiente estruturado adequadamente de forma que viabilize o processo para práticas que fomentem a aquisição de um repertório motor mais diversificado trará maiores possibilidades de desenvolvimento integral das crianças (ROSA NETO et al., 2007). Destacamos, entre outros, a apropriação dos sentidos sobre as diferentes interações e práticas culturais que as crianças vivenciam na infância e na educação infantil (EI), fazendo do brincar uma dimensão constitutiva dos seres humanos, essencial na formação do ser humano nesta fase de ensino (WAJSKOP, 2012).

\footnotetext{
1 Kunz (2006; p.78) destaca que "ninguém pode isolar o movimento dos objetos ou do ser que se-movimenta". O autor em pauta ainda considera que, em análises de movimento humano, os objetos a serem analisados não devem ser os movimentos unicamente, mas também, o "sujeito que se movimenta, a situação ou contexto em que o movimento é realizado e o significado ou sentido relacionado ao movimento" (p.79). O novo olhar para o sujeito, traduz-se pelo conceito da expressão alemã "Sich-bewegen" que significa "próprio-movimento" sendo difundida em português, a partir de Elenor Kunz, como "se-movimentar".
} 
Entendemos as crianças como pessoas com direitos, capazes de aprender a manifestar suas vontades sobre a realidade, tornando-se pessoas integrais, com percepção, expressão, sentido, crítica e criatividade, em uma visão holística e integrada, reconhecendo-as como cidadãs que adquirem e atribuem significado para culturas vividas (NICOLIETO et al., 2019). E, neste conjunto, trazemos à tona as instituições educativas como espaços privilegiados para aprender e brincar.

A partir da promulgação na legislação brasileira da Constituição Federal de 1988, reconhece-se que é um direito da criança o acesso à creche, onde a mesma faria parte do sistema de ensino e também das políticas públicas educacionais (OLIVEIRA, 2002). Com base nesta perspectiva, surge então O Estatuto da Criança e do Adolescente (ECA) (BRASIL, 1990), Lei de Diretrizes e Bases da Educação (BRASIL, 1996), Referencial Curricular Nacional da Educação Infantil (RCNEI) (BRASIL, 1998). Porém, ainda há muitas questões no que tange à legislação e pedagogia nesta etapa de ensino, sinalizando avanços, permanências e necessário investimento do poder público.

Contudo, neste trabalho, interessa-nos destacar a importância da instituição educativa nesta fase da criança e a presença de espaços para brincar e "se-movimentar."

Ressaltamos que o brincar e as interações são eixos norteadores das práticas pedagógicas que compõem a proposta curricular da EI (BRASIL, 2010) e que essas dimensões buscaram ser continuamente observadas e consideradas (LEITE; CAUPER; MARTINS, 2016).

Em outro sentido, o texto da Base Nacional Comum Curricular (BNCC), dando forma ao que já havia sido preconizado pelas Diretrizes Curriculares Nacionais para a Educação Infantil (DCNEI), considera que o currículo da EI deve ser organizado por campos de experiência, que são compreendidos como "[...] um arranjo curricular adequado à educação da criança de 0 a 5 anos e 11 meses quando certas experiências, por ela vivenciadas, promovem a apropriação de conhecimentos relevantes" (BRASIL, 2016; p. 62).

Ao analisarem a potencialidade dos campos de experiência, Carvalho e Guizo (2015) afirmam que tal organização preconiza o contexto de vida das crianças e as situações com as quais elas se deparem no cotidiano como mola propulsora para novas experiências. Nesta linha de pensamento, González e Schwengber (2012) refletem que diferentes formas de experimentar as possibilidades corporais devem permear as aprendizagens nesta etapa da vida que se faz na EI. E, neste conjunto de possibilidades, daremos destaque a ginástica e seus elementos constitutivos.

Diante do exposto, este estudo versa sobre o(s) uso(s) de um parque infantil por crianças no(s) tempo(s) de brincar espontâneo e quais movimentos são realizados por elas nos equipamentos que constituem este espaço. 
O lócus da pesquisa foi o projeto de extensão "Pipocando na educação infantil" desenvolvido pelo Grupo de Estudos e Práticas da Ginástica (GEPG) da Universidade Federal dos Vales do Jequitinhonha e Mucuri (UFVJM) em parceria com o Centro Municipal de Educação Infantil Bom Jesus (CMEI Bom Jesus), ambas instituições situadas na cidade de Diamantina, MG. A ação extensionista objetivou construir um parque infantil com materiais alternativos (pneus) com equipamentos que favorecessem a realização de elementos gímnicos de forma livre, criativa e lúdica (LOPES; NOBRE; NIQUINI, 2020).

A opção pela ginástica seu deu pelo fato dela apresentar conteúdo que permeia movimentos simples, vivenciados em nosso cotidiano e presentes nas brincadeiras infantis tradicionais livres e experimentadas (AYOUB, 2003), possíveis de serem observados em recreios escolares infantis (PIZANI; RINALD, 2010). Seus fundamentos compõem uma série de padrões de movimentos que, além de serem elementares para a progressão em habilidades mais complexas nos diversos tipos desta prática, também possibilitam desenvolver a consciência e o domínio corporal do sujeito, facilitando, posteriormente, a evolução em diferentes manifestações da cultura corporal, de acordo com a faixa etária apropriada (COSTA et al., 2020; NUNOMURA, 2016; RUSSEL; NUNOMURA, 2002; TSUKAMOTO; NUNOMURA, 2005).

Dentre as diversas orientações sobre como trabalhar a ginástica em estágio inicial - antes de abordar especificidades de alguma modalidade (TSUKAMOTO; NUNOMURA, 2005) - a proposta de Russel (2010) organiza o conteúdo gímnico em padrões básicos de movimento (PBMs) de acordo com suas características biomecânicas, conforme ilustra o quadro abaixo:

Quadro 01 - Síntese dos PBMs propostos por Russel (2010).

\begin{tabular}{|c|c|c|c|l|}
\hline Movimento & $\begin{array}{c}\text { Descrição } \\
\text { biomecânica }\end{array}$ & Tipos & $\begin{array}{c}\text { Descrição } \\
\text { biomecânica }\end{array}$ & $\begin{array}{l}\text { Exemplos de variações } \\
\text { do movimento }\end{array}$ \\
\hline \multirow{2}{*}{$\begin{array}{c}\text { Movimentos } \\
\text { Estacionários }\end{array}$} & \multirow{2}{*}{ CM dentro da BA } & Apoio & $\begin{array}{c}\text { CM está acima da } \\
\text { BA }\end{array}$ & $\begin{array}{l}\text { Sobre os pés, as mãos, } \\
\text { diferentes partes do corpo } \\
\text { (quadril, pernas, costas, } \\
\text { etc.) }\end{array}$ \\
\cline { 3 - 5 } & & Movimento estável & $\begin{array}{l}\text { CM está acima e na } \\
\text { extremidade da BA }\end{array}$ & $\begin{array}{l}\text { Sobre os pés, as mãos, } \\
\text { diferentes partes do corpo } \\
\text { (cabeça, ombros, quadril, } \\
\text { etc.) }\end{array}$ \\
\cline { 3 - 5 } & & Sovimento instável & CM está abaixo da \\
BA & $\begin{array}{l}\text { Segurando com as mãos, } \\
\text { as pernas }\end{array}$ \\
\cline { 3 - 5 } & & & Movimento estável & \\
\hline
\end{tabular}




\begin{tabular}{|c|c|c|c|c|}
\hline \multirow{2}{*}{$\begin{array}{l}\text { Não-estacionário } \\
\mathrm{s} \text { lineares }\end{array}$} & \multirow{2}{*}{$\begin{array}{c}\mathrm{CM} \\
\text { constantemente } \\
\text { fora da BA, se } \\
\text { move em linha reta }\end{array}$} & Salto & $\begin{array}{l}\text { CM sai da BA com } \\
\text { um único movimento } \\
\text { explosivo }\end{array}$ & $\begin{array}{l}\text { Com um dos pés, os dois } \\
\text { pés, as mãos, outras } \\
\text { partes do corpo (quadril, } \\
\text { costas, etc.) }\end{array}$ \\
\hline & & Deslocamento & $\begin{array}{l}\text { CM sai da BA com } \\
\text { movimentos } \\
\text { repetitivos }\end{array}$ & $\begin{array}{l}\text { Sobre os pés, as mãos, em } \\
\text { suspensão; em diferentes } \\
\text { direções }\end{array}$ \\
\hline \multirow{2}{*}{$\begin{array}{l}\text { Movimentos } \\
\text { Não-estacionário } \\
\text { s rotacionais }\end{array}$} & \multirow{2}{*}{$\begin{array}{c}\mathrm{CM} \\
\text { constantemente } \\
\text { fora da BA, se } \\
\text { move em rotação }\end{array}$} & Rotação & $\begin{array}{l}\text { Giro em torno do } \\
\text { eixo de rotação } \\
\text { interno }\end{array}$ & $\begin{array}{l}\text { No eixo longitudinal, } \\
\text { transversal ou } \\
\text { ântero-posterior }\end{array}$ \\
\hline & & Balanço & $\begin{array}{l}\text { Giro em torno do } \\
\text { eixo de rotação } \\
\text { externo }\end{array}$ & Em suspensão, apoio \\
\hline Aterrissagens & $\begin{array}{c}\text { CM retorna para a } \\
\text { BA }\end{array}$ & Aterrissagens & $\begin{array}{c}\text { Retorno do } \\
\text { movimento } \\
\text { Não-estacionário }\end{array}$ & $\begin{array}{l}\text { Sobre os pés, as mãos, } \\
\text { costas; em rotação }\end{array}$ \\
\hline
\end{tabular}

$\mathrm{CM}=$ Centro de Massa, $\mathrm{BA}=\mathrm{Base}$ de apoio.

Fonte: Elaborado pelas autoras, adaptado de Russel (2010).

Tais movimentos devem ser trabalhados em suas mais diversas possibilidades (variando as superfícies onde são realizados como direções, planos, eixos de rotações, utilizando materiais ou não, etc.), de forma livre - permitindo o sujeito explorar e descobrir variações, e de maneira orientada pelo professor(a) - com o intuito de permitir a execução mais eficiente da habilidade; respeitando a indicação metodológica para cada faixa etária.

Desta forma, a construção de cada uma das estruturas (brinquedos) no parque do referido projeto foi planejada com o intuito de propiciar, de forma espontânea, a realização dos PBMs (LOPES; NOBRE; NIQUINI, 2020).

É importante salientar que, no contexto escolar, a presença da ginástica deve objetivar a vivência de experiências significativas com o intuito de ampliar as possibilidades de movimentação de forma prazerosa, auxiliando o autoconhecimento dos alunos (COSTA et al., 2020). Neste sentido, seu processo de ensino-aprendizagem pode se dar a partir do mundo de movimento dos alunos, o que potencializa a autonomia dos sujeitos por meio de ações reflexivas e significativas que se relacionam com o seu cotidiano (SERON, et al. 2007).

Organizar o conteúdo gímnico em grandes temas e trabalhá-los por meio de estratégias de resolução de problemas pode fazer com que o aluno desenvolva competências de movimentos de forma mais segura e se sinta familiarizado com a ginástica, o que pode ser uma base importante 
para introdução de uma pedagogia crítica condizente com a faixa etária dos sujeitos (COSTA et al., 2020).

Em estudo conduzido por Pizani e Rinaldi (2010) verificou-se a presença de diferentes movimentos gímnicos nas brincadeiras espontâneas realizadas durante o recreio escolar de uma instituição pública, fato que levou as autoras acreditarem que a ginástica, embora negligenciada nas aulas de educação física, faz parte da história de vida das crianças, evidenciando um possível desejo pela aprendizagem sistematizada desta manifestação da cultura corporal.

Para Brasileiro e Marcassa (2008), as expressões corporais são mediadas e construídas pela cultura, ou seja, a gestualidade incorpora referências relacionadas com a história de vida dos sujeitos, o que inclui desde a educação recebida no ambiente familiar até as experiências vivenciadas na escola, moldando o "sujeito-corpo" em relação com o mundo e com os outros (p. 199).

Neste sentido, alinhados com o entendimento da importância do brincar e do se-movimentar, este estudo se propôs observar a presença de elementos gímnicos explorados no uso do parque infantil da referida instituição escolar, a qual não conta com a presença do(a) professor(a) de educação física no seu quadro de funcionários. Nossa intenção foi identificar os movimentos realizados pelas crianças de forma espontânea e organizá-los a partir da perspectiva dos PBMs (RUSSEL, 2010).

Acreditamos que a manifestação dos movimentos gímnicos é de suma importância para o desenvolvimento infantil no que tange a evolução para prática da ginástica de forma sistematizada futuramente e também para a aquisição de amplo repertório motor para outras práticas corporais, pois se referem aos movimentos fundamentais que enriquecem o conhecimento corporal e facilitam processo de ensino-aprendizagem. Sendo assim, identificar o se-movimentar gímnico por meio de brincadeiras espontâneas indica que as crianças estão sendo estimuladas de maneira enriquecedora.

\section{MÉTODOS}

O trabalho desenvolvido foi de natureza qualitativa (LUDKE; ANDRÉ, 1986). A partir da utilização da técnica de observação sistemática e direta que, segundo Lakatos e Marconi (1992, p. 43) é um tipo de observação que "[...] utiliza os sentidos na obtenção de determinados aspectos da realidade", buscou-se compreender experiências corporais gímnicas presentes no cotidiano do momento livre no parque construído no CMEI Bom Jesus.

Os sujeitos da pesquisa foram 32 crianças, entre dois e três anos de idade, de duas turmas de maternal III. Segundo Gallahue, Ozmun e Goodway (2013), esta faixa etária contempla os 
movimentos fundamentais em estágio inicial e elementar, visto que seriam as primeiras tentativas e subsequentes experimentações.

O mapeamento dos movimentos foi realizado duas vezes por semana, durante os meses março, abril e maio de 2019, totalizando 10 momentos de observações. Uma das pesquisadoras acompanhou o momento de brincar livre no parque se posicionando em determinado espaço onde não interferisse na dinâmica das crianças. Os movimentos realizados em cada uma das estruturas (brinquedos) foram descritos em diários de campo (NICONIELO, 2019), no qual a pesquisadora anotou todos os tipos de movimentações com a intenção de classificá-los em padrões gímnicos. Os registros foram acompanhados de fotografias e filmagens com o objetivo de auxiliar a apreciação e análise posteriormente (COSTA, 2002).

Após finalizada a coleta de dados, a análise foi realizada por meio da categorização das informações descritas nos diários de campo à luz da teoria que fundamenta a proposta dos PBMs (RUSSEL, 2010).

O estudo respeitou todas as exigências de pesquisa envolvendo seres humanos, com aprovação do Comitê de Ética em Pesquisa da UFVJM (Parecer 2.850.668).

\section{RESULTADOS E DISCUSSÃO}

A figura 1 apresenta as estruturas (brinquedos) em que os movimentos realizados foram analisados.

Figura 1 - Brinquedos construídos no parque da escola. 


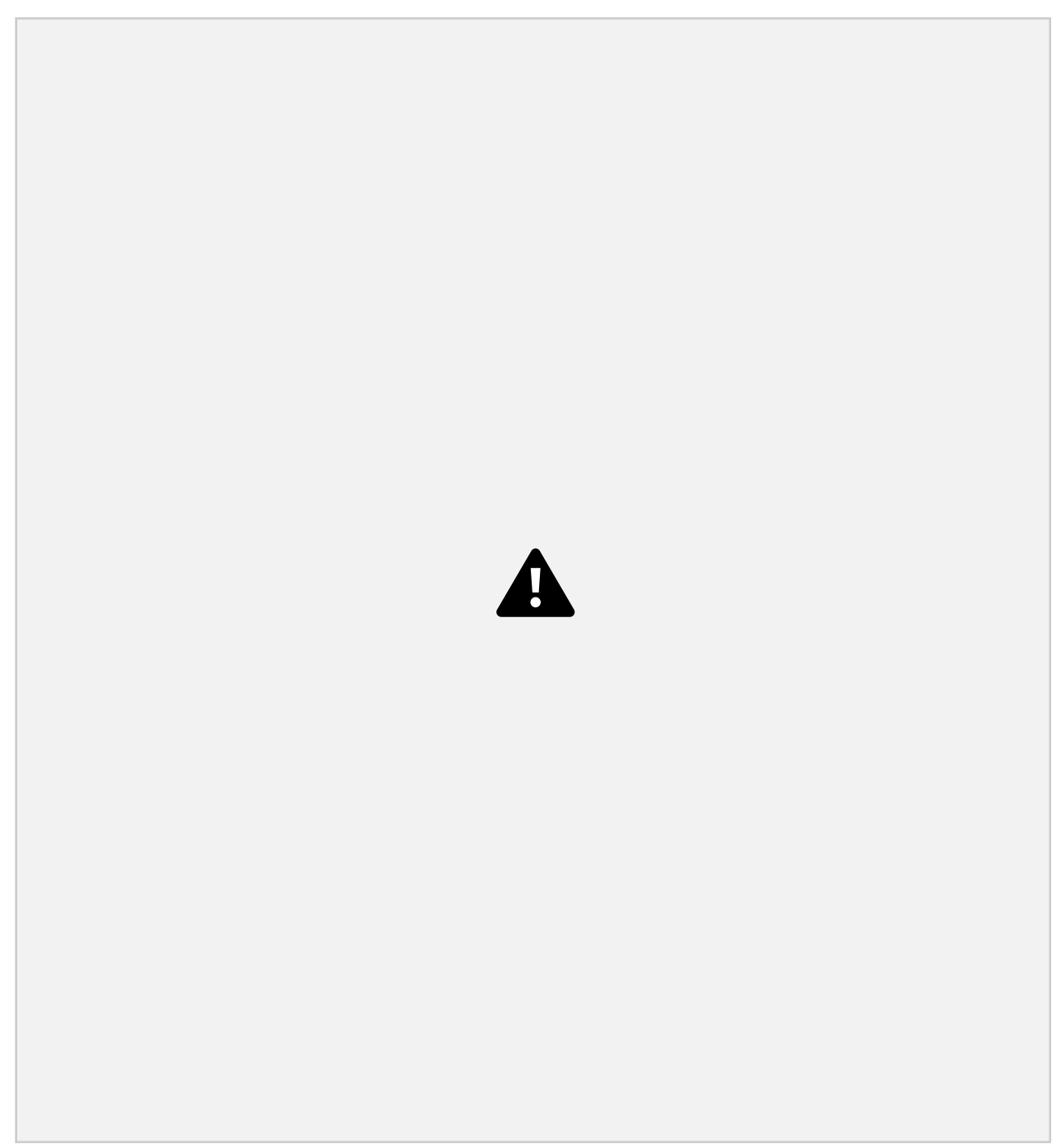

Fonte: Registros fotográficos presentes nos diários de campo.

$\mathrm{Na}$ sequência, apresentamos os resultados da análise feita a partir dos movimentos observados.

Quadro 2 - Categorização dos movimentos realizados pelas crianças em cada brinquedo.

\begin{tabular}{|c|c|}
\hline Brinquedo & Movimentos observados realizados pelas crianças \\
\hline 1.Moto & $\begin{array}{l}\text { aterrissagem sobre um e dois pés; movimento estacionário em equilíbrio e em apoio; } \\
\text { salto dos pés. }\end{array}$ \\
\hline 2.Escorrega & $\begin{array}{l}\text { aterrissagem sobre os pés e sobre as mãos; deslocamento sobre o quadril, } \\
\text { sobre o tronco em decúbito ventral e dorsal e por toda a parte do corpo (arrastando); } \\
\text { movimento estacionário em apoio; rotação no eixo longitudinal. }\end{array}$ \\
\hline 3.Trampolim & $\begin{array}{l}\text { aterrissagem sobre os pés e sobre o quadril; combinação entre salto dos pés e rotação } \\
\text { no eixo longitudinal; movimentos estacionários em equilíbrio; saltos dos pés, de um } \\
\text { pé e do quadril. }\end{array}$ \\
\hline $\begin{array}{l}\text { 4.Acerto de } \\
\text { argolas }\end{array}$ & $\begin{array}{l}\text { aterrissagem sobre os pés; outras possibilidades de movimentos (lançamentos de } \\
\text { argola no tronco, envolver a argola no corpo); saltos dos pés. }\end{array}$ \\
\hline
\end{tabular}




\begin{tabular}{|c|l|}
\hline $\begin{array}{c}\text { 5.Trepa } \\
\text { Trepa }\end{array}$ & $\begin{array}{l}\text { aterrisagem sobre os pés; deslocamento dos pés e mãos (quadrupedia) e dos joelhos; } \\
\text { movimentos estacionários em apoio; saltos dos pés. }\end{array}$ \\
\hline $\begin{array}{c}\text { 6.Rampa de } \\
\text { Escalada }\end{array}$ & $\begin{array}{l}\text { aterrisagem sobre os pés; deslocamento sobre os pés, mãos e joelhos (quadrupedia); } \\
\text { movimentos estacionários em apoio. }\end{array}$ \\
\hline 7.Argolas & $\begin{array}{l}\text { aterrissagem sobre os pés; balanço em suspensão; movimento estacionário em } \\
\text { suspensão. }\end{array}$ \\
\hline 8.Toca & $\begin{array}{l}\text { aterrisagem sobre os pés; deslocamento sobre os pés e mão (quadrupedia); } \\
\text { movimentos estacionários em equilíbrio; saltos dos pés. }\end{array}$ \\
\hline 9.Balanço & aterrissagem sobre os pés; balanço em apoio; rotação no eixo longitudinal. \\
\hline 10.Ônibus & aterrisagem sobre um pé; movimento estacionário em apoio e equilíbrio. \\
\hline 11.Trilha & $\begin{array}{l}\text { aterrissagens sobre os pés; deslocamento sobre os pés e sobre os pés e mãos } \\
\text { (quadrupedia); movimento estacionário em equilíbrio; saltos dos pés. }\end{array}$ \\
\hline
\end{tabular}

Fonte: Elaborado pelas autoras.

Os resultados demonstram que os PBMs realizados pelas crianças de forma espontânea nas 11 estruturas dispostas no parque foram variados e contemplam quase todas as possibilidades gímnicas elencadas por Russel (2010).

Percebe-se que há variações nas formas de aterrissar (sobre diferentes partes do corpo), de saltar (com um e dois pés), de se deslocar (sobre mãos, pés, quadril, tronco, joelhos), de girar (no eixo longitudinal sobre diferentes partes do corpo, em apoio, em suspensão), de balançar (em apoio e suspensão) e de se movimentar sem deslocamento (em apoio, equilíbrio e suspensão).

Apenas rotações no eixo transversal e ântero-posterior não foram observadas, fato que pode ser justificado pela ausência de estruturas que sejam mais adequadas para a biomecânica desses PBMs. Outro fator que atribuímos poderia ser o viés cultural, no qual tentativas de rotação nestes eixos podem ser desestimuladas pela atribuição de riscos por parte de quem cuida das crianças (profissional da escola presente na hora do parque).

Mesmo sem a presença destes dois tipos de rotações, consideramos que a diversidade de PBMs observada nos resultados abrangem elementos importantes para o desenvolvimento infantil, pois também contemplam os movimentos fundamentais, apresentados em estágio elementar e maduro no modelo de ampulheta proposto por Gallahue, Ozmun e Goodway (2013). Segundo os autores, tais movimentos evoluem à medida que o desenvolvimento e a maturação acontecem no sujeito e também funcionam como suporte para aquisição de outras habilidades posteriormente, podendo ser utilizados para a futura prática esportiva de lazer.

Ambas as propostas concordam que a vivência contínua das habilidades básicas leva a novas experimentações, estimulando a tentativa, a ousadia no se-movimentar e a combinação entre os 
movimentos, fatores essenciais para o desenvolvimento motor (GALLAHUE; OZMUN; GOODWAY, 2013; RUSSEL, 2010).

Logo, podemos eleger o momento no parque como um trabalho inicial de base motora que, se for continuado de forma sistematizada futuramente (na faixa etária adequada), poderá facilitar a evolução no processo de ensino-aprendizagem de elementos das diferentes manifestações da ginástica. Para Nunomura (2016), o trato com os elementos corporais básicos da ginástica proporciona o desenvolvimento da consciência e domínio corporal, fatores que devem ser priorizados antes de adentrar a prática gímnica sistematizada.

Além dos fundamentos gímnicos básicos, as crianças realizaram, ao mesmo tempo (e sem perceberem), uma preparação corporal, a qual compreende o desenvolvimento de capacidades físicas (flexibilidade, força abdominal, agilidade dentre outras) e desempenho motor em habilidades importantes para a infância (lançar, saltar, correr, dentre outras) (CONDESSA, 2019) que contribuem sobremaneira para que os movimentos gímnicos sejam aprendidos de forma mais segura e eficiente, pois um físico bem preparado tem condições de evoluir mais facilmente da execução de elementos simples para os mais complexos (ARAÚJO, 2012; NUNOMURA et al., 2016; RUSSEL, 2010; RUSSEL; NUNOMURA, 2002). Este pensamento é consoante com o entendimento de autores do desenvolvimento motor que compreendem a relevância de ter um conhecimento global da criança e de suas características visto que o conhecimento de como ela se desenvolve e movimenta, aprimora suas capacidades físicas e motoras e, portanto, a motiva para aderir a brincadeiras corporais e à atividade física (GALLAHUE; OZMUN; GOODWAY, 2013).

Os movimentos sobre as mãos, sejam estacionários ou em deslocamento, reportam aos princípios dos elementos gímnicos em posição invertida, como a parada de mãos e a estrela, por exemplo. Tais habilidades demandam desenvolvimento de força dos membros superiores, equilíbrio e coordenação, que precisam ser estimulados para que as crianças aprimorem valências importantes para conseguirem aprender essas evoluções futuramente, pois são consideradas mais difíceis (ARAÚJO, 2012; NUNOMURA et al., 2016).

Como este tipo de movimento não é comum em atividades orientadas na EI, visto que na faixa etária em questão ainda estão em fase de aquisição de movimentos fundamentais em estágio elementar (GALLAHUE; OZMUN; GOODWAY; 2013), acreditamos que espaços que possibilitem a vivência do apoio sobre as mãos durante brincadeiras espontâneas contribuem de forma riquíssima para ampliação do repertório motor e desenvolvimento das capacidades físicas das crianças, assim como para a experimentação de diferentes sensações durante a movimentação corporal. 
Da mesma forma, uma série de outros constructos foi vivenciada, tais como a percepção sinestésica e corporal, noção de espaço e do corpo no espaço, visto que as crianças experimentaram passar por dentro dos pneus de diferentes tamanhos e nas estruturas que constituem o parque. Além disso, experimentaram mudança constante do centro de massa nos deslocamentos distintos que as estruturas possibilitaram, sobre e no pneu, sobre estrutura elástica instável e estável, corroborando o entendimento de oferecer possibilidades para ampliação do repertório motor (GALLAHUE; OZMUN; GOODWAY, 2013).

É preciso salientar que as estruturas construídas no parque foram projetadas para permitir a utilização mediante a constituição do brinquedo, tais como se balançar no balanço, saltar no trampolim, etc. No entanto, foi possível observar que as estruturas permitiram transcender as possibilidades de movimentos pré-estabelecidos.

Os diários de campo apontam que, num primeiro momento, ao chegarem ao parque, às crianças realizaram os movimentos específicos de cada brinquedo, ou seja, realizavam corporalmente os elementos para os quais o brinquedo foi projetado, conforme registrado nas observações. Porém, no decorrer do tempo de utilização do parque, verificou-se que elas extrapolaram o se-movimentar específico de cada estrutura, criando brincadeiras que permitiram experimentações corporais para além daquelas esperadas nos brinquedos, de maneira a evidenciar o quanto o livre brincar é permeado pela criatividade infantil (LEITE; CAUPER; MARTINS, 2016).

Citamos como exemplo, o brinquedo 1, "Moto", o qual foi projetado para ser utilizado sentado, mas que permitiu às crianças subirem com os pés na estrutura, se equilibrarem, saltarem em direção ao chão e aterrissarem sobre os pés. No brinquedo 2, "Escorrega", as crianças se deslocaram se arrastando sobre diferentes partes do corpo (além do quadril, que era o movimento esperado), realizando inclusive rotação no eixo longitudinal durante a descida. Na estrutura 4, "Acerto de argolas", as argolas foram colocadas no chão para brincar de amarelinha, momento em que também realizaram movimentos de salto e aterrissagem com um e dois pés, além de permanecerem em posição estacionária tentando manter o equilíbrio.

Este fato corrobora o entendimento de que o brincar traz sentidos e significados próprios da cultura infantil (TONIETTO; GARANHANHI, 2017). Reforça ainda o potencial criativo que a brincadeira livre proporciona, corroborando dados do estudo de Rinaldi e Pizani (2010) que identificou que o momento de liberdade e espontaneidade presente no período educacional permite movimentar-se, explorar o próprio corpo, descobrir novas formas gestuais, superar seus próprios limites. Também remonta as experiências corporais anteriores e a criatividade individual de cada criança, condições que podem ser estimuladas e desenvolvidas ao oferecermos um ambiente diversificado que provoque a interação com o meio através de diferentes maneiras, proporcionando 
uma rica aprendizagem motora com respostas complexas de movimentos a medida que ocorre o desenvolvimento (GALLAHUE; OZMUN; GOODWAY, 2013; NUNOMURA, 2002; PETRI; LIMA RODRIGUES, 2018).

A brincadeira fora das estruturas durante a hora do parque foi rara, fato observado com pouca frequência e de forma reincidente em apenas algumas crianças. Verificou-se também que, em muitos momentos, as crianças simplesmente andavam e corriam em diferentes direções, de forma aleatória, juntas ou perseguindo umas às outras, reforçando o entendimento de que nesta faixa etária, o sujeito é movimento.

Movimentos de muito contato não aconteceram com frequência. Geralmente, optavam por andar ou correr livremente sem se prender as mãos dos colegas, inclusive por orientação da professora generalista com o propósito de evitar possíveis leões e conflitos. O comportamento das profissionais presentes na hora do parque evidenciou uma preocupação excessiva com a segurança das crianças, fato que, em diversos momentos, limitou as possibilidades das experimentações.

O dia-a-dia de uma instituição de EI é dinâmico, reserva surpresas e é marcado pela espontaneidade das crianças (LEITE; CAUPER; MARTINS, 2016). Elas brincam juntas, mas, na maioria das vezes, não se prendem muito tempo na mesma atividade, se mantendo em constante movimento junto com os colegas ou seguindo algum líder que sempre orienta a brincadeira. Este fato evidencia o poder do brincar na formação humana, pois desde pequenos emergem líderes. As virtudes e valores se constituem nos grupos pelo brincar (OTTA, 2017), visto que no desejo de se divertir, esse brincar se transforma em uma ferramenta de comunicação (JURDI; SILVA; LIBERMAN 2018; TONIETTO; GARANHANI, 2017). Através de suas manifestações é possível identificar iminentes conflitos, diferenças de personalidades, elementos culturais aprendidos no convívio com outros indivíduos e a forma com que os sujeitos veem o mundo e o traduz através das brincadeiras e do lúdico (COLLA, 2019; NICOLIETO, 2019).

Desta forma, corroboramos o pensamento de autores que defendem a ideia do brincar coletivamente (WAJSKO, 2018; COLA, 2019), pois ver o colega fazer algum movimento novo pode encorajar as crianças a experimentarem diferentes formas de se moverem, assim como pode estimular comportamentos positivos como a cooperação ao ajudarem o outro a executar determinado movimento, o respeito ao esperarem a sua vez de utilizar o brinquedo, dentre outros (JURDI; SILVA; LIBERMAN, 2018), além de possibilitar evolução da exploração do movimento previsto nos brinquedos para o inesperado, criado por meio das livres experimentações.

Por fim, ressaltamos que no momento em que esta pesquisa foi desenvolvida, a presença do parque na escola era recente. Acreditamos que com o tempo, a dinâmica de experimentações corporais utilizando os brinquedos poderá ser ampliada, favorecendo a execução dos PBMs de 
forma mais completa e até combinada, expandindo as sensações que podem ser propiciadas através da vivência do movimento gímnico.

\section{CONSIDERAÇÕES FINAIS}

Este trabalho se propôs a observar a presença de elementos gímnicos explorados de forma espontânea no uso do parque infantil em uma dada instituição da EI que não tem inserida a figura do professor de Educação Física.

Verificamos que os movimentos gímnicos, na perspectiva dos PBMs, foram explorados de diferentes formas no parque da escola, diversificando eixos, planos, direções, variações entre utilização dos pés, mãos e diferentes partes do corpo, etc. Tais experiências foram vivenciadas de forma lúdica e contextualizadas com a realidade da criança, uma vez que foram propiciadas dentro de um ambiente pertencente ao universo infantil, corroborando estudos que fazem esta orientação para o trato da ginástica na EI (OLIVEIRA; LOPES; NOBRE, 2019).

Compreendemos que o brincar permeia ações distintas como imitar, perceber, mostrar, criar inventar, repetir, expressar sentimentos, sensações, emoções descritas nas Bases Nacionais Curriculares (BRASIL, 2017) além de movimentar, corroborando autores que defendem estas práticas presentes no cotidiano das crianças (PIZANI, RINALDI, 2010) em distintos contextos (AYOUB, 2003; MARCASSA, 2004; DARIDO; SANCHEZ NETO, 2005; NISTA -PICCOLOa; NISTA -PICCOLOb ; MOREIRA, 2012; COSTA et al., 2016; LOPES, 2015; LOPES et al., 2015; SANTOS et al., 2018; OLIVEIRA; LOPES; NOBRE, 2019; LOPES; NOBRE; NIQUINI, 2019).

Logo, entendemos que ter um parque nas dependências da escola, para além de reverenciar a cultura corporal infantil, considera a infância com respeito ao tempo da criança, as possibilidades de ela se-movimentar, se descobrir, experimentar. Defendemos políticas públicas que priorizam a valorização da cultura corporal nestes espaços, revelando a importância da infância para a formação dos sujeitos.

Para além da perspectiva do se-movimentar com olhar focado no sujeito do movimento e não no movimento do sujeito (KUNZ, 1991), acreditamos que o processo de construção do parque de materiais alternativos (LOPES; NOBRE; NIQUINI, 2020) e a possibilidade de exploração livre neste espaço e do brincar livre colaboraram significativamente para a melhoria da qualidade do ambiente da escola, extrapolando o que toca o movimento. A alegria, as risadas, a algazarra para chegar logo percebidas nos momentos que antecedem a ida ao parque são evidências que não nos 
possibilitam mensurar e descrever a importância deste ambiente, mas que ficam sempre gravadas na memória do observador e daqueles que fazem parte do contexto da EI.

Aqui ressaltamos a importância de atividades sistematizadas e direcionadas com presença do professor de Educação Física para propiciar práticas distintas que considerem a prática da cultura corporal infantil visto que entendemos que posições invertidas, ainda que possam fazer parte do cotidiano infantil requerem mais ousadia, mais consciência corporal, quesitos que poderiam ser estimulados em presença de prática sistematizada. Corroboramos autores que defendem as atividades dirigidas (WEISBERG, ZOSH 2018) e sistematizadas, com presença de professor de Educação Física (AYOUB 2001) visto que o professor regente responsável pela turma não possui formação específica para estimular as habilidades motoras fundamentais (AYOUB, 2005) e menos ainda, desenvolver o trato com a ginástica (OLIVEIRA, LOPES, NOBRE, 2019). Entretanto, reforçamos também a importância do brincar livre no cotidiano das crianças da EI para o desenvolvimento integral e holístico.

\section{REFERÊNCIAS}

ARAÚJO, Carlos. Manual de ajudas em ginástica. $2^{\mathrm{a}}$ ed. Várzea Paulista, SP: Fontoura, 2012.

AYOUB, Eliana. Reflexões sobre a educação física na educação infantil. Revista Paulista de Educação Física, São Paulo, supl. 4, p. 53-60, 2001.

AYOUB, Eliana. Narrando experiências com a Educação física na educação infantil. Revista Brasileira de Ciências do Esporte, Campinas, vol. 26, n. 3, p. 143-158, maio 2005.

AYOUB, Eliana. A Ginástica geral e educação física escolar. Campinas: UNICAMP, 2003.

BRASIL, MEC; CNE, CEB. Diretrizes curriculares nacionais para a educação infantil. Resolução CEB-CNE, v. 1, 2010.

BRASIL. Ministério da Educação. Base Nacional Comum Curricular. Brasília, DF: MEC, 2016. Disponível em: http://basenacionalcomum.mec.gov.br.

BRASIL. Lei no 8.069, de 13 de julho de 1990. Dispõe sobre o Estatuto da Criança e do Adolescente e dá outras providências. Estatuto da Criança e do Adolescente. Diário Oficial da União, Brasília, 16 jul. 1990.

BRASIL, Lei n. 9.394/96, de 20 de dezembro de 1996. Estabelece as diretrizes e bases da educação nacional. Disponível: http://www.planalto.gov.br/ccivil_03/leis/

L9394.htm Acesso em: 24 de julho de 2016.

BRASIL. Ministério da Educação e do Desporto. Secretaria de Educação Fundamental. Referencial curricular nacional para a educação infantil / Ministério da Educação e do Desporto, Secretaria de Educação Fundamental, Brasília: MEC/SEF, v. 3,1998.

BRASIL. Ministério da Educação. Base nacional comum curricular, Brasília: MEC/SEB, 2017. Disponível em: http://basenacionalcomum.mec.gov.br/images/BNCC_EI_EF_110518_versaofinal_site.pdf. 
BRASILEIRO, Lívia Tenorio; MARCASSA, Luciana Pedrosa. Linguagens do corpo: dimensões expressivas e possibilidades educativas da ginástica e da dança. Pro-Posições, vol. 19, n. 3, p. 195-207, 2008.Disponível em: http://dx.doi.org/10.1590/S0103-73072008000300010.

CONDESSA, Isabel Cabrita. Um estudo de interações de perceção e desempenho-imagem corporal, capacidade físicas e motoras-com um grupo de menin@s do $1 .^{\circ}$ ciclo. Revista INFAD de Psicología. International Journal of Developmental and Educational Psychology., vol. 5, n. 1, p. 167-176, 2019. Disponível em: https://revista.infad.eu/index.php/IJODAEP/article/view/1581

CARVALHO, Rodrigo Saballa de; GUIZZO, Bianca Salazar. Políticas de Educação Infantil: conquistas, embates e desafios na construção de uma Pedagogia da Infância. Revista de Educação Pública, Cuiabá, vol. 27, n. 66, p. 771-791, 2018. Disponível em:

https://periodicoscientificos.ufmt.br/ojs/index.php/educacaopublica/article/view/4563

COLLA, Rodrigo Avila. O brincar e o cuidado nos espaços da educação infantil: desenvolvendo os animais que somos. Revista Brasileira de Estudos Pedagógicos, vol. 100, n. 254, p. 111-126, 2019. Disponível em: http://dx.doi.org/10.24109/2176-6681.rbep.100i254.3956.

CORSARO, William A. Sociologia da infância. Tradução de Lia Gabriele Regius Reis. São Paulo: Artmed, 2011,384 p.

COSTA, Sidney Alves. O Diário de Campo como dialética intersubjetiva. IN: D. C. A. WHITAKER (org.). Sociologia Rural: questões metodológicas emergentes. Presidente Venceslau: Letras à Margem, p. 151-158, 2002.

COSTA, Andrize Ramires, et al. "Brincar e se-movimentar" da criança: a imprescindível necessidade humana em extinção? Corpoconsciência, 2016a, 19.3: 45-52.Disponível em:

https://periodicoscientificos.ufmt.br/ojs/index.php/corpoconsciencia/article/view/4148.

COSTA. Andrize Ramires et al. Ginástica na escola: por onde ela anda professor? Conexões, Campinas, SP vol. 14 n. 4 p. 76-96, 2016b. Disponível em:

https://periodicos.sbu.unicamp.br/ojs/index.php/conexoes/article/view/8648071

COSTA, Andrize Ramires et al. A transformação didático-pedagógica da ginástica para as crianças pelo "brincar e se-movimentar". Motrivivência, vol. 32, n. 63, p. 01-16, 2020. Disponível em:

https://periodicos.ufsc.br/index.php/motrivivencia/article/view/2175-8042.2020e72360

DARIDO, Suraya. Cristina.; SANCHEZ NETO, Luiz. O contexto da educação física na escola. In: DARIDO, Suraya Cristina.; RANGEL, Irene Conceição Andrade. (org.). Educação física na escola: implicações para a prática pedagógica. Rio de Janeiro: Guanabara Koogan, 2005.

GALLAHUE, David L.; OZMUN, John C.; GOODWAY, Jackie D. Compreendendo o desenvolvimento motor-: bebês, crianças, adolescentes e adultos. AMGH Editora, 2013.

GASPAR, Bianca Serafim; DE CARVALHO, Richarles Souza. Imagens de infância em Peter Pan de James Barrie. Revista Saberes Pedagógicos, 2017, 2.1: 259-274.Disponível em:

http://dx.doi.org/10.18616/rsp.v2i1.3714

GONZALES, Fernando Jaime; SCHWENGBER, Maria Simone Vione. Escola e Educação Física nos anos iniciais: especificidades e conhecimentos. Práticas pedagógicas em Educação Física: espaço, tempo e corporeidade. Erechim: Edelbra. p. 131. 2012. 
JURDI, Andrea Perosa Saigh; SILVA, Carla Cilene Baptista; LIBERMAN, Flavia. Inventários das brincadeiras e do brincar: ativando uma memória dos afetos. Interface (Botucatu), Botucatu, vol. 22, n. 65, p. 603-608, Apr. 2018. Disponível em: https://doi.org/10.1590/1807-57622016.0978

KUNZ. Elenor. Educação física: ensino e mudanças. Ijuí: Unijuí, 1991.

KUNZ, Elenor. Transformação didático-pedagógica do esporte. Coleção educação física, 7ed. -Ijuí: Ed. Unijuí, 2006.

LAKATOS, Eva Maria; MARCONI, Marina. Fundamentos de Metodologia Científica. São Paulo: Atlas, 1992.

LEITE, Jaciara Oliveira; CAUPER, Dayse Alisson Camara; MARTINS, Poliana Carvalho. Saberes e movimento - o diálogo entre educação física e educação infantil: reflexões a partir da prática pedagógica. Cadernos de Formação RBCE, p. 9-19, mar. 2016. Disponível em:

http://revista.cbce.org.br/index.php/cadernos/article/view/2193.

LOPES, Priscila, NOBRE, Juliana Nogueira, NIQUINI, Cláudia Mara. Parque na escola: uso (s) de materiais alternativos e ações coletivas para a Educação infantil. Revista Educação Popular, Uberlândia, vol.19, n.2, p.214-227, Maio-ago, 2020. Disponível em: https://doi.org/10.14393/REP-2020-51638.

LOPES, Priscila; NOBRE, Juliana Nogueira Pontes; NIQUINI, Cláudia Mara. O conteúdo "ginástica" nos processos seletivos dos Institutos Federais de Minas Gerais. Revista Thema, Pelotas, vol. 16, n. 3, p. 537-548, 2019. Disponível em: https://doi.org/10.15536/thema.V16.2019.537-548.1502.

LOPES, Priscila. et al. Ginástica para todos e literatura: realidade, possibilidades e criação. Conexões, Campinas, vol. 13, n. especial, p. 127-146, maio 2015. Disponível em:

https://doi.org/10.20396/conex.v13iEsp..8637581

LOPES, Priscila. Ginasticando: parceria e possibilidades da ginástica na escola. Revista Elos: Diálogos em Extensão, Viçosa, vol. 4, n. 2, p. 38-42, dez. 2015. Disponível em: https://doi.org/10.21284/elo.v4i2.76

LÜDKE, Menga; ANDRÉ, Marli A. Pesquisa em educação: abordagens qualitativas. São Paulo: EPU, 1986.

MARCASSA, Luciana. Metodologia do ensino da ginástica: novos olhares, novas perspectivas. Pensar a Prática, Goiânia, vol. 7, n. 2, p. 171-186, jul.-dez. 2004. Disponível em: https://doi.org/10.5216/rpp.v7i2.94.

NISTA-PICCOLO, Vilma Lení; MOREIRA, Wagner Wey. Corpo em movimento na educação infantil. São Paulo: Cortez, 2012a.

NISTA-PICCOLO, Vilma Lení; MOREIRA, Wagner Wey. Esporte como conhecimento e prática nos anos iniciais do ensino fundamental. São Paulo: Cortez, 2012b.

NISTA-PICCOLO, Vilma Lení; MOREIRA, Wagner Wey. Esporte para a saúde nos anos finais do ensino fundamental. São Paulo: Cortez, 2012c.

NUNOMURA, Mírian. Uma alternativa de conteúdo para um programa de Iniciação á ginástica Artística: A experiência no Canadá. Motriz, Jan-Jun 2000 , vol. 6n. 1, pp.31-34.

NUNOMURA, Myrian (org.) Fundamentos das Ginásticas. $2^{\mathrm{a}}$ ed. Várzea Paulista, SP: Fontoura, 2016.

NICOLIELO, Maria Elisa et al. Brincar como prática social da pequena infância em contexto de Educação Infantil: aprender para a vida. Educação Unisinos, vol. 23, n. 2, p. 352-366, 2019. Disponível em:

https://doi.org/10.4013/edu.2019.232.16849 
OLIVEIRA, Zilma Ramos. Educação Infantil: fundamentos e métodos. São Paulo. SP: Cortez, 2002.

OLIVEIRA, Michelly Tatiane; LOPES, Priscila; NOBRE, Juliana Nogueira Pontes. Ginástica na educação infantil: uma análise das publicações do Fórum Internacional de Ginástica Para Todos. Conexões, Campinas, vol. 17, p. 1-19, 2019. Disponível em: https://doi.org/10.20396/conex.v17i0.8653360.

OTTA, Emma. Brincar na perspectiva psicoetológica: implicações para pesquisa e prática. Psicologia USP, v. 28, n. 3, p. 358-367, 2017. Disponível em: http://dx.doi.org/10.1590/0103-656420160122

PIZANI, Juliana; BARBOSA-RINALDI, Ieda Parra. Cotidiano escolar: a presença de elementos gímnicos nas brincadeiras infantis. Journal of Physical Education, vol. 21, n. 1, p. 115-126. Disponível em:

https://periodicos.uem.br/ojs/index.php/RevEducFis/article/view/7732

PETRI, Ivonilda Soares; LIMA RODRIGUES, Raquel Flores. Um olhar sobre a importância do brincar e a repercussão do uso da tecnologia nas relações e brincadeiras na infância. Research, Society and

Development, vol. 9, n. 9, p. e326997368-e326997368, 2020.Disponível em:

https://doi.org/10.33448/rsd-v9i9.7368

NETO, Francisco Rosa et al. Desenvolvimento motor de crianças com indicadores de dificuldades na aprendizagem escolar. Revista Brasileira de Ciência e Movimento, vol. 15, n. 1, p. 45-52, 2008. Disponível em: https://portalrevistas.ucb.br/index.php/RBCM/article/viewFile/729/732

RUSSEL, Keith. Gymnastics foundations. Canada: Ruschkin Publishing, 2010.

RUSSEL, Keith; NUNOMURA, Myrian. Uma alternativa de abordagem da ginástica na escola. Revista UEM, Maringá, vol. 13, n. 1, p. 123-127, 2002.

SERON, Taiza Daniela, et al. A ginástica na educação física escolar e o ensino aberto. Revista da Educação Física/UEM. Maringá, vol. 18, n. 2, p. 115-125, 2. Set. 2007. Disponível em:

https://periodicos.uem.br/ojs/index.php/RevEducFis/article/view/3268

SOUZA, Elizabeth Paolielo. M. Ginástica geral: uma área do conhecimento da Educação Física I

Elizabeth Paoliello Machado de Souza. -- Campinas, SP: [ s. n. ], 1997.

SANTOS, Thyago Thacyano de Souza et al. A Ginástica Para Todos nas aulas de educação física: um estudo de caso. Conexões, vol. 16, n. 4, p. 450-467, 2018. Disponível em:

https://doi.org/10.20396/conex.v16i4.8653973

SILVA, Raynara Rodrigues da Cruz, et al. A importância da Educação Física no desenvolvimento motor e cognitivo da criança. Anais da Jornada de Educação Física do Estado de Goiás (ISSN 2675-2050), 2018, 1.1: $39-43$.

TONIETTO, Marcos Rafael; GARANHANI, Marynelma Camargo. A cultura infantil e a relação com os saberes da Educação Física na escola. Movimento, v. 23, n. 2, p. 517-528, 2017. Disponível em: https://doi.org/10.22456/1982-8918.66236

TSUKAMOTO, Mariana Harumi Cruz; NUNOMURA, Myrian. Iniciação esportiva e infância: um olhar sobre a ginástica artística. Revista Brasileira de Ciências do Esporte, vol. 26, n. 3, 2005. Disponível em: http://www.oldarchive.rbceonline.org.br/index.php/RBCE/article/view/166

WAJSKOP, Gisela. Brincar na Educação Infantil: uma história que se repete. $9^{\mathrm{a}}$ ed. (Coleção Questões da Nossa Época, no 34. - São Paulo: Cortez, 2012.

WEISBERG, Deena Skolnick; ZOSH, Jennifer. M. How guided play promotes early childhood learning. Encyclopedia on Early Childhood Development, eds RE Tremblay, M. Boivin, and R. Peters 
(Montreal: Centre of Excellence for Early Childhood Development and Strategic Knowledge Cluster on Early Child Development.), p. 1-4, 2018.

\section{NOTAS DE AUTOR}

\section{AGRADECIMENTOS}

Agradecemos a Secretaria Municipal de Educação do município de Diamantina, a diretora da instituição pela realização do projeto. Agradecemos também a Pró Reitoria de extensão e Cultura PROEXC da Universidade Federal dos Vales do Jequitinhonha e Mucuri-UFVJM pela bolsa concedida.

\section{CONTRIBUIÇÃO DE AUTORIA}

Concepção do manuscrito: J.N. P Nobre, P. Lopes

Coleta de dados: A. F. Silva

Análise de dados: P Lopes, A.F. Silva, J.N.P.Nobre

Discussão dos resultados: J.N.P.Nobre, C.M.Niquini, P.Lopes

Produção do texto: A.F.Silva, J.N.P.Nobre, P.Lopes, C.M.Niquini

Revisão e aprovação: C.M Niquini, J.N.P.Nobre, P.Lopes

Caso necessário veja outros papéis em: https://casrai.org/credit/

\section{FINANCIAMENTO}

Pró Reitoria de extensão e Cultura PROEXC da Universidade Federal dos Vales do Jequitinhonha e Mucuri-UFVJM pela bolsa concedida.

CONSENTIMENTO DE USO DE IMAGEM - Não se aplica.

\section{APROVAÇÃO DE COMITÊ DE ÉTICA EM PESQUISA}

Declaramos que a pesquisa contou com aprovação do Comitê de Ética em Pesquisa da Universidade Federal dos Vales do Jequitinhonha e Mucuri sob o parecer 2.850.668.

CONFLITO DE INTERESSES - Declaramos que não há conflitos de interesse.

\section{LICENÇA DE USO}

Os autores cedem à Motrivivência - ISSN 2175-8042 os direitos exclusivos de primeira publicação, com o trabalho simultaneamente licenciado sob a Licença Creative Commons Attribution Non-Comercial ShareAlike (CC BY-NC SA) 4.0 International. Esta licença permite que terceiros remixem, adaptem e criem a partir do trabalho publicado, desde que para fins não comerciais, atribuindo o devido crédito de autoria e publicação inicial neste periódico desde que adotem a mesma licença, compartilhar igual. Os autores têm autorização para assumir contratos adicionais separadamente, para distribuição não exclusiva da versão do trabalho publicada neste periódico (ex.: publicar em repositório institucional, em site pessoal, publicar uma tradução, ou como capítulo de livro), com reconhecimento de autoria e publicação inicial neste periódico, desde que para fins não comerciais e compartilhar com a mesma licença.

\section{PUBLISHER}

Universidade Federal de Santa Catarina. Programa de Pós-Graduação em Educação Física. LaboMídia - Laboratório e Observatório da Mídia Esportiva. Publicado no Portal de Periódicos UFSC. As ideias expressadas neste artigo são de responsabilidade de seus autores, não representando, necessariamente, a opinião dos editores ou da universidade. 


\section{EDITORES}

Mauricio Roberto da Silva, Giovani De Lorenzi Pires, Rogério Santos Pereira.

\section{EDITORA DE SEÇÃO}

Bianca Poffo.

\section{REVISÃO DO MANUSCRITO E METADADOS}

João Caetano Prates Rocha; Keli Barreto.

\section{HISTÓRICO}

Recebido em: 11 de novembro de 2020.

Aprovado em: 28 de fevereiro de 2021. 